\title{
MECHANISTIC RESPONSES OF ASPHALT CONCRETE OVERLAY OVER JOINTED PLAIN CONCRETE PAVEMENT USING FINITE ELEMENT METHOD
}

\author{
AMADOU OURY DIALLO ${ }^{1}$, MUHAMMET VEFA AKPINAR ${ }^{2^{\star}}$ \\ ${ }^{1,2}$ Dept of Civil Engineering, Karadeniz Technical University, \\ Trabzon, Turkey
}

Received 4 September 2019; accepted 5 May 2020

\begin{abstract}
This study focused on the development of a three-dimensional Finite Element Model of an asphalt concrete overlaid on a jointed plain concrete pavement to assess the mechanical behaviour of the pavement under traffic load. The objective of this study was to determine the influence of different asphalt concrete thickness, asphalt concrete modulus, the interface bond between the asphalt concrete and the Portland cement concrete layer, Portland cement concrete modulus, and joint width on the tensile strain at the bottom of the asphalt overlay. The results showed that changes in the pavement parameters result in a large range of variations on the magnitude of pavement responses. The magnitude of the longitudinal tensile strain at the bottom of the overlay varied between $25 \mu \varepsilon$ and $460 \mu \varepsilon$. Asphalt concrete thickness, interface contact condition, and asphalt concrete modulus parameters had the most influence on the pavement responses. The interface bonding condition was significant, regardless of the thickness of the surface layer.
\end{abstract}

Keywords: asphalt overlay, Finite Element Model (FEM), Portland cement concrete (PCC), reflective cracking.

* Corresponding author. E-mail: mvakpinar@ktu.edu.tr

Amadou Oury DIALLO (ORCID ID 0000-0002-0484-0395)

Muhammet Vefa AKPINAR (ORCID ID 0000-0001-7912-8274)

Copyright (C) 2020 The Author(s). Published by RTU Press

This is an Open Access article distributed under the terms of the Creative Commons Attribution License (http://creativecommons.org/licenses/by/4.0/), which permits unrestricted use,

distribution, and reproduction in any medium, provided the original author and source are credited. 


\section{Introduction}

Portland cement concrete (PCC) pavement is known for its longlasting durability service life with regular maintenance. However, despite their good performance, PCC pavements overtime reach the end of their service life due to the combination of weather conditions and traffic loading. Thus, rehabilitation needs to be carried out before the pavement reach this level. There are several techniques for rehabilitating deteriorated PCC pavement. Depending on the traffic volume, placing an overlay is the most used method to restore the pavement structural capacity and also improving the ride quality (Huang, 1993). The placement of asphalt concrete (AC) overlay is considered to be the most common technique used for rigid pavement rehabilitation (Freeman \& Board, 2002; Pavement Consultancy Services, 1991). The good performance of this method of rigid pavement rehabilitation is affected negatively by the apparition of cracks knows as "reflective cracking". These cracks are the results of high strain concentration in the asphalt overlay due to the bending and shearing movements of the underlying slabs at the joints or cracks present in the old structure, caused by temperature changes, moisture cycles, and traffic loads (Lytton, 1989; Lytton, Tsai, Lee, Luo, Hu, \& Zhou, 2010; Nunn, 1989). Reflected crack leads to premature failure of the overlaid pavement, and it severely impacts the performance and the serviceability of the road (Francois, Larson, Pennsylvania, Borchert, Braun, Dustin, \& Manheim, 1982).

The critical responses are the concentration of tensile strains at the bottom of the AC layer at the vicinity of cracks and joints. Several researchers have been effectuated to investigate the sensitivity of these critical responses to the changes in the pavement characteristic parameters (structure, material properties, layer interactions) by using accelerated pavement testing facilities, laboratory studies, and numerical analysis. Some studies, for instance, focused on the interface contact condition between the asphalt and the existing PCC layer (Al-Qadi, Carpenter, Leng, Ozer, \& Trepanier, 2009; Ozer, Al-Qadi, Wang, \& Leng, 2012). Some have studied the design of the Hot Mix Asphalt (HMA) and the thickness of the AC and also the use of reflective cracking countermeasures such as paving fabrics interlayer (Amini, 2005; Fallah \& Khodaii, 2015; Shen, Zhang, Wang, \& Huang, 2017; Sobhan \& Tandon, 2008). All these parameters were found to be affecting the performance of the overlay on a different level.

This study compares pavement characteristics cited below on the performance of an asphalt overlay over jointed Portland cement concrete pavement.

- AC overlay thickness;
Mechanistic

Responses of Asphalt Concrete Overlay Over Jointed Plain Concrete Pavement Using Finite Element Method 
- AC overlay modulus;

- bonding interface condition between the AC and the PCC layers;

- modulus of the existing PCC pavement;

- dimensions of the joints in the existing pavement.

\section{Materials and methods}

A 3D Finite Element model (3D FEM) able to simulate the responses of an AC overlaid on an existing jointed plain concrete pavement (JPCP) with various parameters under traffic axle loading was created to accomplish the study objectives. The ANSYS APDL 16.0 was used to simulate the pavement responses. The Finite Element modelling included the creation of the pavement geometric model, the attribution of the materials, the meshing, the creation of the contact between the layers, and the application of loads and boundary conditions.

\subsection{Geometry model}

As this study focused on analysis rather than design, a typical fourlayer pavement structure consisting of an AC overlaid on an existing JPCP resting on an aggregate base, and a subgrade was adopted (Figure1). The typical slab length in a JPCP is around $6 \mathrm{~m}$. However, since the critical responses are located near to the joint, only half of the slab from either side of a $1 \mathrm{~cm}$ width joint was modelled. This assumption allowed modelling a 3D pavement section of $6 \mathrm{~m}$ length in traffic

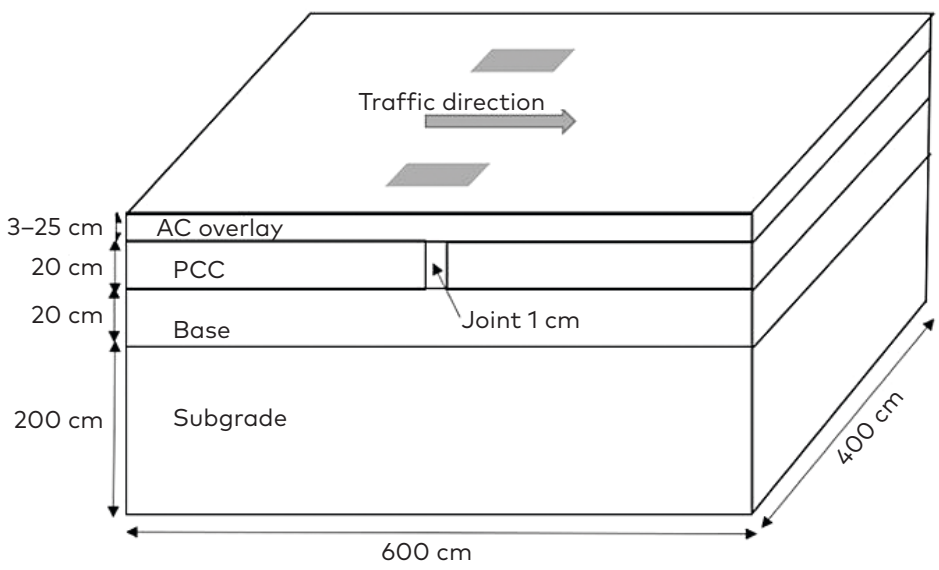

Figure 1. Pavement model geometry 
direction (longitudinal direction), and $4 \mathrm{~m}$ in the transverse direction. The total depth of the existing pavement was assumed to be $2.4 \mathrm{~m}$ consisting of $0.2 \mathrm{~m}$ of the PCC layer, $0.2 \mathrm{~m}$ of the base layer and $2.0 \mathrm{~m}$ of the subgrade layer. Different overlay thicknesses varying from $3 \mathrm{~cm}$ to $25 \mathrm{~cm}$ were modelled. The joint width also varied from $0 \mathrm{~cm}$ to $2 \mathrm{~cm}$ to determine the joint opening effect.

\subsection{Element types and material properties}

The model created for this study was an assembly of solid elements with different thicknesses and material properties. Both eight nodes solid element (also known as a brick element) and 20-node solid element are to model the layers of the composite pavement. Using the eight nodes solid element is less time-consuming (Cable, Fanous, Ceylan, Wood, Frentress, Tabbert, ..., \& Gopalakrishnan, 2005; Williamson, 2015). However, the 20-node solid element provides more accurate results despite a higher requirement for the computational resource. Kumara, Tia, Wu, \& Choubane (2003) used 20-node solid elements in his study of ultra-thin white topping pavement layers (Kumara, Tia, Wu, \& Choubane, 2003). The 20-node solid 186 elements were used in this study for all the elements. All layer materials were assumed to be linear, elastic and isotropic (Lytton, Tsai, Lee, Luo, Hu, \& Zhou, 2010; Sobhan \& Tandon, 2008). Since the asphalt material stiffness depends on the temperature (low elastic modulus in hot weather and high elastic modulus in cold weather) and the design mixture of the HMA, four different asphalt moduli were considered to determine its effect on the responses in the AC layer. Three different PCC modulus were also considered when analysing its effect on the pavement responses. Table 1 gives the material properties of the different layers.
Mechanistic

Responses of Asphalt Concrete Overlay Over Jointed Plain Concrete Pavement Using Finite Element Method

Table 1. Properties of the materials

\begin{tabular}{llc}
\hline \multicolumn{1}{c}{ Layer } & \multicolumn{1}{c}{ Elastic modulus, MPa } & Poisson's ratio \\
\hline Asphalt concrete & $2000,3500^{*}, 5000,10000$ & 0.35 \\
\hline Portland cement concrete & $34000,28000^{*}, 20000$ & 0.20 \\
\hline Granular base & 250 & 0.40 \\
\hline Subgrade & 150 & 0.45 \\
\hline
\end{tabular}

Note: * unless otherwise stated, the value used. 


\subsection{Boundaries conditions and loading}

The size and quality of the model mesh affect the rightness of the result. Studies have shown that fine mesh gives more accurate results even though it requires much time to analyse. The fine mesh was used for the surface and a relatively coarse mesh for the subgrade (Williamson, 2015) (Figure 2).

In ANSYS the contacts are generated by pair. For the node-surface contact, the node is "contact" and the surface a "target". For the surface to surface contact both "contact" and "target" are surfaces and the user has to specify which surface is contact or target. In this study "surface to surface" contact was used. There are several types of interaction behaviour for the "surface to surface" contact in ANSYS: standard, rough, bonded. The "bonded always" was used to simulate fully bonding interfaces, and the "standard" contact with a coefficient of friction equal to zero was used for unbonded interfaces. In this study, all the layers in the existing pavement were assumed to be fully bonded. Whereas fully bonded and unbonded interaction between the AC overlay and the PCC was considered (Thompson \& Thompson, 2017).

All nodes at the bottom of the subgrade were restrained in all directions. The nodes on the sides were restrained in $X$-direction for traffic direction sides and Z-direction for pavement width sides (Williamson, 2015). The standard axle load of $80 \mathrm{kN}$ with a tire pressure of $689 \mathrm{kPa}$ was adopted (Lytton, Tsai, Lee, Luo, Hu, \& Zhou, 2010). This study used uniform pressure applied to rectangular areas with dimensions approximating those of a single tire contact area. This loading concept of considering uniform pressure over the entire length of the wheel has been used successfully in previews studies (Lytton, Tsai, Lee, Luo, Hu, \& Zhou, 2010). A static axle-load single tire was selected for this study (Figure 3).

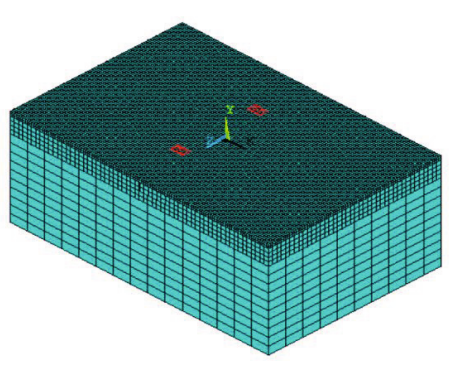

Figure 2. Model mesh

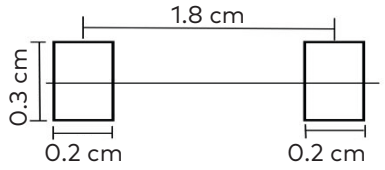

Figure 3. Axle load and tires contact dimensions 
1)

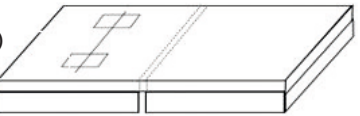

2)

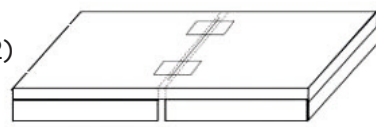

3)

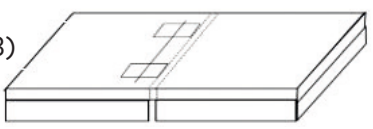

Mechanistic

Responses of Asphalt

Concrete Overlay

Over Jointed Plain

Concrete Pavement

Using Finite Element

Method

Figure 4. Axle load positions in respect of the joint

Axle load was placed at three different positions on the surface to find the critical axle load position on the pavement responses (Figure 4). The axle load was centered for the transverse direction of the pavement.

\section{Results and discussions}

\subsection{Critical axle load position and critical response}

The results showed that the critical position of the axle load was when the load was applied to one side of the joint. The longitudinal strains were found to be the most critical compared to the transverse ones, $113 \mu \varepsilon$ and $69 \mu \varepsilon$ for longitudinal and transverse strain, respectively (Figure 5). The longitudinal tensile strains at the different positions were $73 \mu \varepsilon$ (for the first two positions) and $113 \mu \varepsilon$.

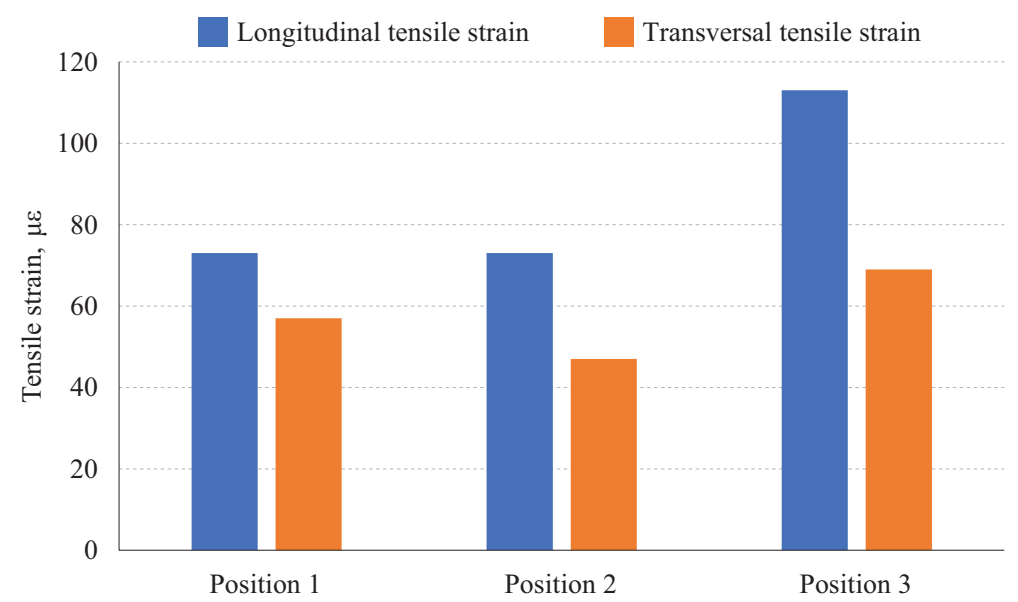

Figure 5. Tensile strain at the bottom of the asphalt concrete overlay versus axle load position 


\subsection{Effect of the asphalt overlay thickness}

Figure 6 shows the variation of the tensile strain at the bottom of the overlay with the AC thickness at different asphalt modulus. For the AC elastic modulus $2000 \mathrm{MPa}, 3500 \mathrm{MPa}, 5000 \mathrm{MPa}$ and $10000 \mathrm{MPa}$ and thickness of $3 \mathrm{~cm}, 6 \mathrm{~cm}, 10 \mathrm{~cm}, 15 \mathrm{~cm}, 20 \mathrm{~cm}$, and $25 \mathrm{~cm}$, the magnitude of the tensile strain varied from $25 \mu \varepsilon$ to $318 \mu \varepsilon$. The range of the pavement response variation due to the changes in the overlay thickness and modulus is large. It confirms that the performance of the overlaid pavement depends a lot on the design of the asphalt concrete overlay.

In terms of tensile strain, regardless of the modulus of the asphalt material when increasing the thickness of the overlay the magnitude of the tensile strain decreases; the reverse is also true, i.e. when the asphalt material modulus increases the tensile strain decreases. For example, for an AC thickness of $10 \mathrm{~cm}$ when increasing the AC modulus of $2000 \mathrm{MPa}$ to $10000 \mathrm{MPa}$, the tensile strain decreases by about $64 \%$. Moreover, for an $\mathrm{AC}$ modulus of $3500 \mathrm{MPa}$ by increasing the AC thickness from $3 \mathrm{~cm}$ to $25 \mathrm{~cm}$, the magnitude of the tensile strain decreases about $84 \%$. Tensile strain due to the change in the $\mathrm{AC}$ modulus decreases when the thickness of the overlay is higher than $10 \mathrm{~cm}$. For example, for an AC thickness of $6 \mathrm{~cm}$ by changing the $\mathrm{AC}$ modulus of $2000 \mathrm{MPa}$ to $10000 \mathrm{MPa}$, the magnitude of the strain decreases by $71 \%$, and the strains for $20 \mathrm{~cm}$ decreases $60 \%$.

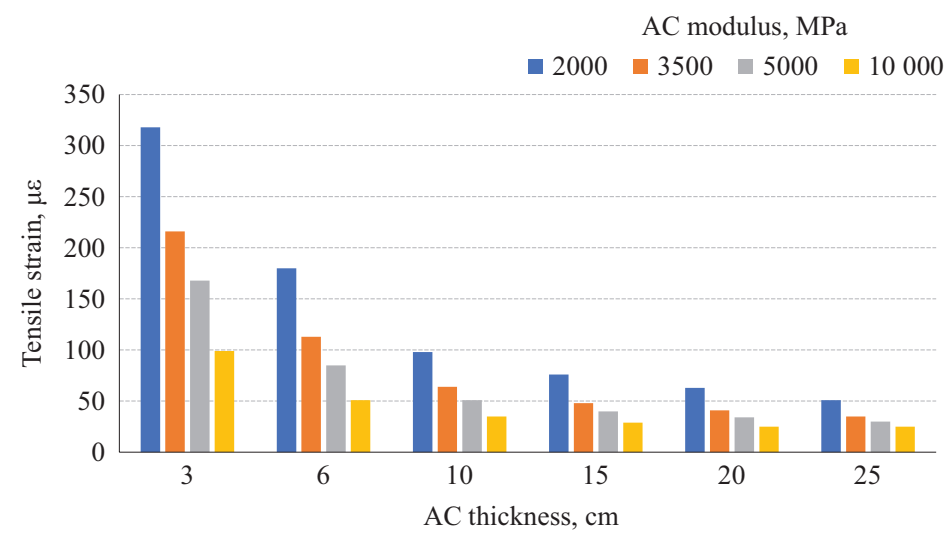

Figure 6. Longitudinal tensile strain at the bottom of the asphalt concrete versus overlay thickness 


\subsection{Bonding effect}

One of the objectives of this study was to investigate the bonding effect between the AC and the PCC under traffic loading. The AC and PCC interface bonding condition is one of the most important factors affecting the performance of the overlay pavement. With a bonded interface, the AC and the existing PCC behave as a unit and the PCC layer carries a significant part of the load. Whereas when unbonded, the PCC only provides a base for the AC overlay. The effect of the AC and PCC bonding condition on the longitudinal tensile strain at the bottom of the AC overlay is shown in Figure 7 and Figure 8.

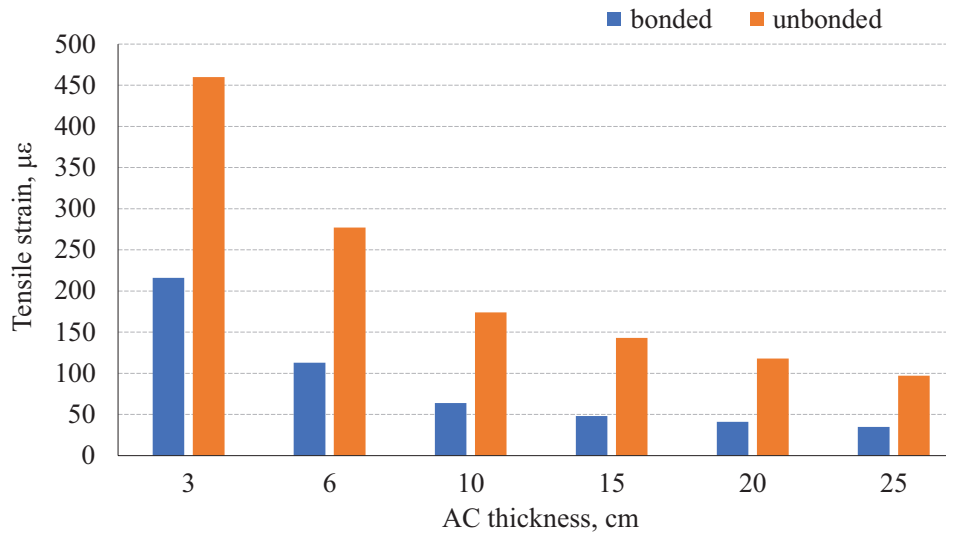

Figure 7. Effect of interfaces contact condition for different overlay thicknesses

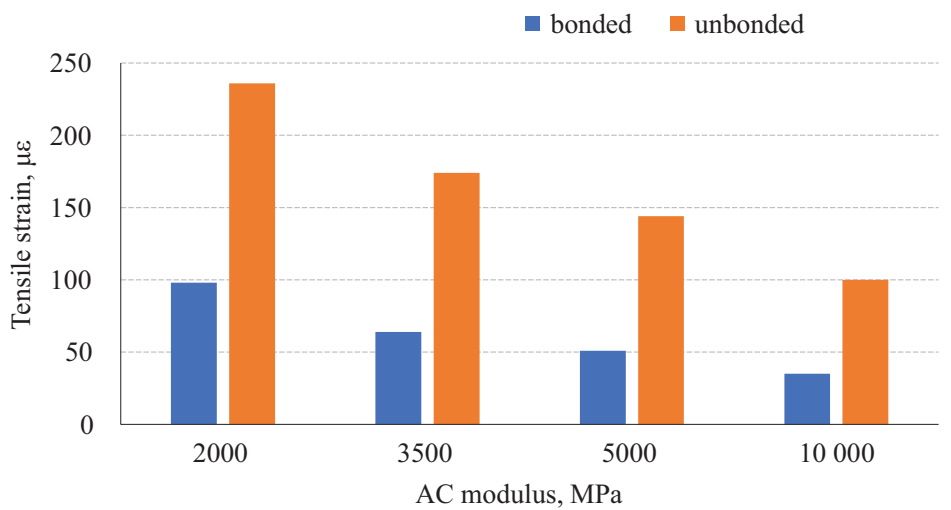

Figure 8. Effect of interface contact condition for different asphalt concrete modulus
Mechanistic

Responses of Asphalt Concrete Overlay Over Jointed Plain Concrete Pavement Using Finite Element Method 
The study results showed that the load-induced tensile strain at the bottom of the overlay was significantly influenced by the AC and PCC bonding condition regardless of the AC thickness or modulus. The magnitude of the tensile strain at the bottom of the overlay increased by $113 \%$ and up to $198 \%$ by changing the interface contact from bonded to unbonded depending on the AC thickness and modulus. For example, for an $\mathrm{AC}$ thickness of $6 \mathrm{~cm}$ and $3500 \mathrm{MPa}$, the values of the strains were $113 \mu \varepsilon$ and $277 \mu \varepsilon$ for bonded and unbonded AC and PCC interfaces respectively.

\subsection{Effect of the existing Portland cement concrete modulus}

The effect of the rigidity of the existing Portland cement concrete (PCC) layer was evaluated by considering three PCC modulus $20000 \mathrm{MPa}, 28000 \mathrm{MPa}$, and $34000 \mathrm{MPa}$. In the analysis, three AC thicknesses $(6 \mathrm{~cm}, 10 \mathrm{~cm}$, and $15 \mathrm{~cm})$ with $3500 \mathrm{MPa}$ AC modulus at different AC and PCC bonding conditions were considered. The effect of the PCC modulus on the tensile strain is shown in Figure 9 and Figure 10. The results showed that by decreasing the PCC modulus, the tensile strain in the AC increase for both bonded and unbonded interfaces. However, the PCC modulus has a small effect on strain in unbonded interface condition, which is logical because in unbonded AC and PCC the AC depends less on the PCC. The tensile strain increased by $8 \%, 11 \%$, and

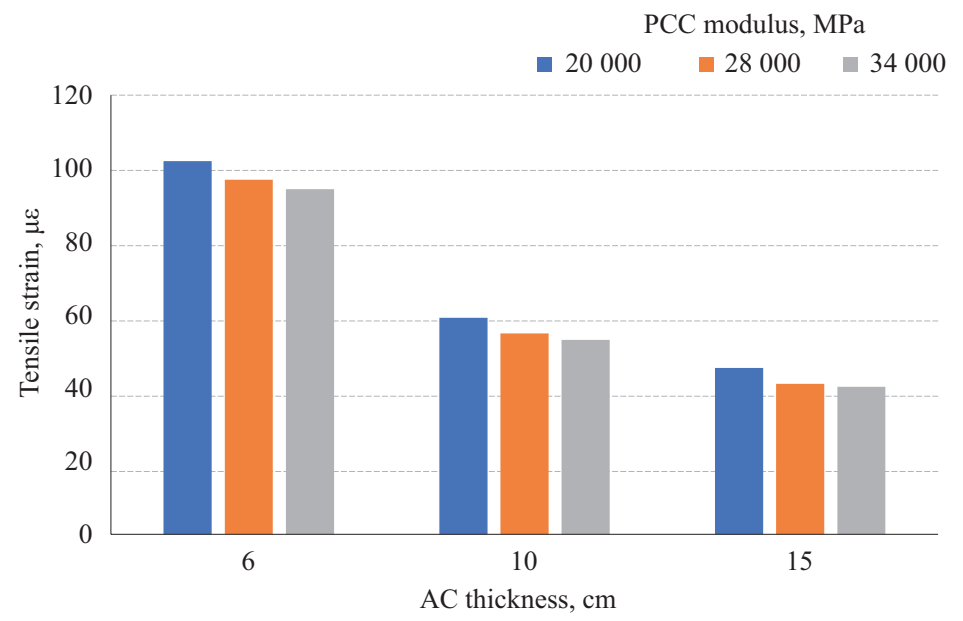

Figure 9. Longitudinal tensile strain variation for bonded condition 


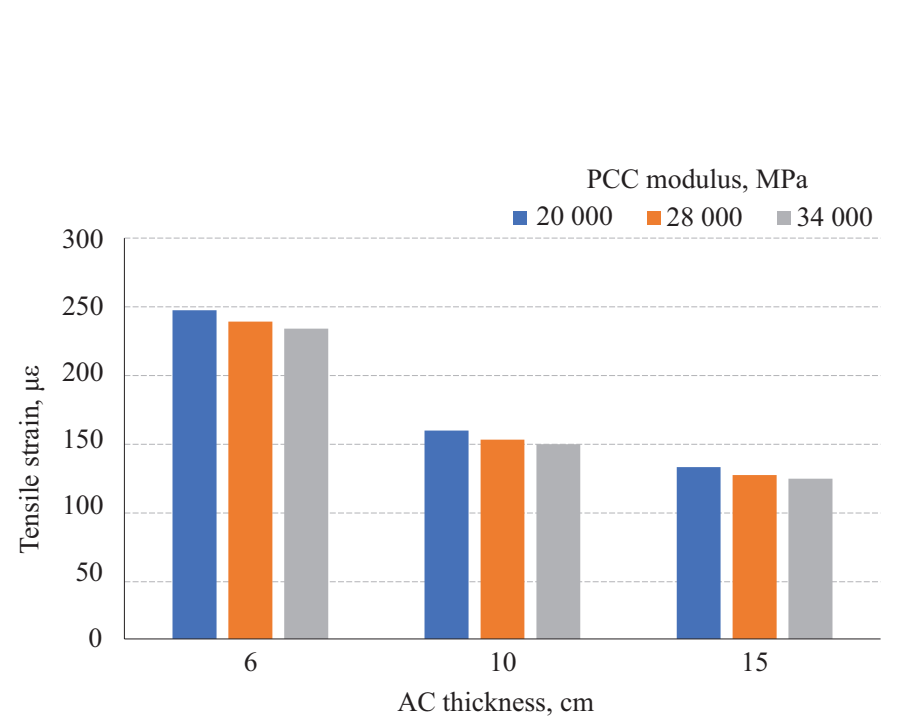

Amadou Oury Diallo, Muhammet Vefa

Akpinar

Mechanistic

Responses of Asphalt

Concrete Overlay

Over Jointed Plain

Concrete Pavement

Using Finite Element

Method

Figure 10. Longitudinal tensile strain for unbonded condition

$13 \%$ for $6 \mathrm{~cm}, 10 \mathrm{~cm}$, and $15 \mathrm{~cm} \mathrm{AC}$ thickness respectively for bonded AC and PCC, and increased by $6 \%$ for $6 \mathrm{~cm} \mathrm{AC}$ and $7 \%$ for $10 \mathrm{~cm}$, and $15 \mathrm{~cm}$ AC for unbonded AC and PCC interfaces.

\subsection{Effect of the dimension of the joint}

The width of the joint or crack is another factor representing the condition of the existing PCC pavement. Figure 11 shows the AC tensile strain at the bottom of the overlay versus the joint width for different

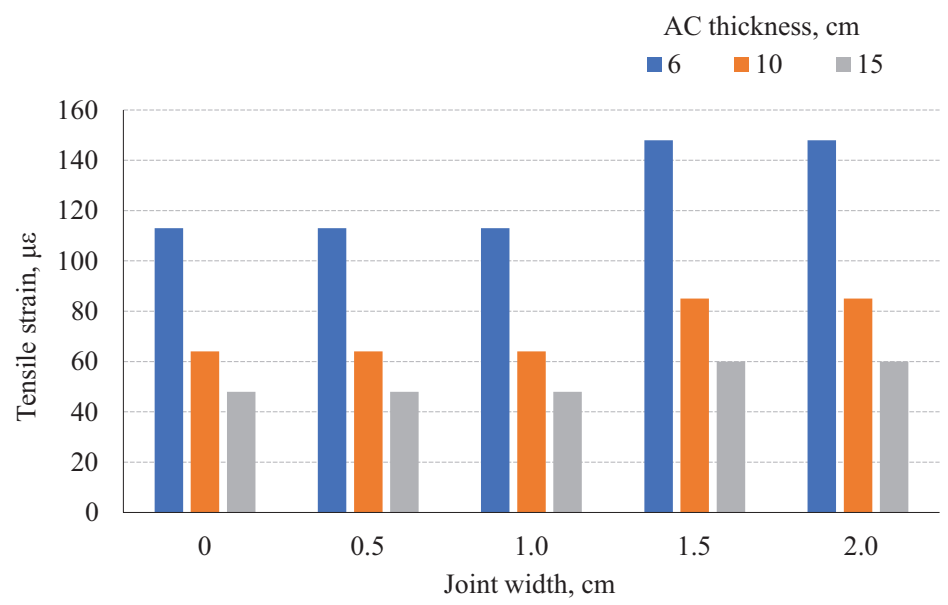

Figure 11. Longitudinal tensile strain at the bottom of the asphalt concrete versus joint width 
overlay thickness. As shown in Figure 11, when increasing the joint width from $0 \mathrm{~cm}$ to $1 \mathrm{~cm}$, the magnitude of the tensile strain remains the same for the same overlay thickness. The value of the tensile strain was $113 \mu \varepsilon, 64 \mu \varepsilon$, and $48 \mu \varepsilon$ for $6 \mathrm{~cm}, 10 \mathrm{~cm}$, and $15 \mathrm{~cm}$ overlay thickness, respectively. However, by widening the joint to $1.5 \mathrm{~cm}$ and $2 \mathrm{~cm}$ the magnitude of the tensile strain increased by $24 \%, 33 \%$, and $25 \%$ for $6 \mathrm{~cm}, 10 \mathrm{~cm}$, and $15 \mathrm{~cm}$ overlay thickness respectively. Therefore, to lessen the magnitude of the strain in the AC overlay due to traffic loading, $1 \mathrm{~cm}$ or smaller joint width is reasonable.

\subsection{Comparison of the variations of the tensile strain}

The effect of variations in different parameters was compared to assess their influence on longitudinal tensile strain at the bottom of the AC overlay. The following procedure was adopted: the pavement reference characteristics and range of variation of each parameter are shown in Table 2.

When determining the influence of a given parameter, the other parameters remain constant and have their reference value. Table 3 shows the variation of the longitudinal tensile strain at the bottom of the AC overlay caused by each investigated parameter.

All the investigated parameters influenced the performance of the pavement at a different level (Table 3). Strain at the bottom of the overlay responded differently to the changes of the pavement characteristics. The level of influence of all the parameters was related to the AC thickness. The variations induced by the changes in AC thickness and

Table 2. Pavement parameters reference characteristics and range of variation

\begin{tabular}{lll}
\hline \multicolumn{1}{c}{ Parameter } & \multicolumn{1}{c}{ Reference } & \multicolumn{1}{c}{ Range } \\
\hline Asphalt concrete thickness & $6 \mathrm{~cm}, 10 \mathrm{~cm}, 15 \mathrm{~cm}$ & $3 \mathrm{~cm}-25 \mathrm{~cm}$ \\
\hline Asphalt concrete modulus & $3500 \mathrm{MPa}$ & $2000 \mathrm{MPa}-10000 \mathrm{MPa}$ \\
\hline $\begin{array}{l}\text { Asphalt concrete } \\
\begin{array}{l}\text { and Portland cement } \\
\text { concrete interface }\end{array}\end{array}$ & Fully bonded & $\begin{array}{l}\text { Fully bonded - fully } \\
\text { unbonded }\end{array}$ \\
\hline $\begin{array}{l}\text { Portland cement concrete } \\
\text { modulus }\end{array}$ & $28000 \mathrm{MPa}$ & $20000 \mathrm{MPa}-34000 \mathrm{MPa}$ \\
\hline \begin{tabular}{l} 
Joint width \\
\hline
\end{tabular} & $1 \mathrm{~cm}$ & $0 \mathrm{~cm}-2 \mathrm{~cm}$ \\
\hline
\end{tabular}


Table 3. Longitudinal tensile strain variation versus pavement parameters

\begin{tabular}{|c|c|c|c|c|}
\hline \multirow{2}{*}{ Parameters } & \multirow{2}{*}{$\begin{array}{c}\text { Asphalt } \\
\text { concrete } \\
\text { thickness, } \\
\text { cm }\end{array}$} & \multicolumn{2}{|c|}{$\begin{array}{c}\text { Microstrain, } \\
\mu \varepsilon\end{array}$} & \multirow{2}{*}{$\begin{array}{c}\text { Difference, } \\
\%\end{array}$} \\
\hline & & $\max$ & $\min$ & \\
\hline $\begin{array}{l}\text { Asphalt concrete } \\
\text { thickness }\end{array}$ & & 216 & 35 & 84 \\
\hline \multirow{3}{*}{$\begin{array}{l}\text { Asphalt concrete } \\
\text { modulus }\end{array}$} & 6 & 198 & 51 & 74 \\
\hline & 10 & 98 & 35 & 64 \\
\hline & 15 & 76 & 48 & 37 \\
\hline \multirow{3}{*}{$\begin{array}{l}\text { Asphalt concrete } \\
\text { and Portland cement } \\
\text { concrete bond }\end{array}$} & 6 & 277 & 133 & 52 \\
\hline & 10 & 174 & 64 & 63 \\
\hline & 15 & 143 & 48 & 66 \\
\hline Portland cement & 6 & 119 & 110 & 8 \\
\hline \multirow[t]{2}{*}{ concrete modulus } & 10 & 69 & 62 & 10 \\
\hline & 15 & 53 & 47 & 11 \\
\hline \multirow[t]{3}{*}{ Joint width } & 6 & 148 & 113 & 24 \\
\hline & 10 & 85 & 64 & 25 \\
\hline & 15 & 60 & 48 & 20 \\
\hline
\end{tabular}

AC modulus were $84 \%$ and $75 \%$, respectively. Portland cement concrete modulus induced a maximum variation of $11 \%$ The variation induced by the joint width was up to $25 \%$

\section{Conclusions}

The objective of this study was to evaluate the performance of an asphalt concrete overlay on an existing jointed plain concrete pavement under axle loading for different asphalt concrete thickness, asphalt concrete modulus, asphalt concrete, and Portland cement concrete interface condition, Portland cement concrete modulus, and joints width. From the study, the following conclusions are drawn.

1. In bonded asphalt concrete and Portland cement concrete by changing the asphalt concrete thickness between $3 \mathrm{~cm}$ and $25 \mathrm{~cm}$ and the asphalt concrete modulus between $2000 \mathrm{MPa}$ to $10000 \mathrm{MPa}$ the longitudinal tensile strain at the bottom of the overlay varied from $25 \mu \varepsilon$ to $318 \mu \varepsilon$. In general, increasing asphalt
Amadou Oury Diallo, Muhammet Vefa

Akpinar

Mechanistic

Responses of Asphalt

Concrete Overlay

Over Jointed Plain

Concrete Pavement

Using Finite Element

Method 
concrete thickness decreased strain values and increasing asphalt concrete modulus decreased stain values.

2. The bond between the asphalt concrete and the existing Portland cement concrete pavement was found to be one of the most important factors in terms of the strain of the pavement. The magnitude of the tensile strain was at least $113 \%$ and increased up to $198 \%$ by changing the interface contact from bonded to unbonded depending on the asphalt concrete thickness and modulus.

3. By decreasing the Portland cement concrete modulus, the tensile strain in the asphalt concrete increased for both bonded and unbonded interfaces. However, the Portland cement concrete modulus had less effect on both strain in the unbonded asphalt concrete and Portland cement concrete interface. The tensile strain increased by $8 \%$ to $13 \%$ for bonded asphalt concrete and Portland cement concrete and increased by $7 \%$ asphalt concrete for unbonded asphalt concrete and Portland cement concrete interfaces depending on the thickness of the asphalt concrete.

4. Increasing joint width from $1 \mathrm{~cm}$ to $2 \mathrm{~cm}$, tensile strain increased about $24 \%$ up to $33 \%$ depending on the asphalt concrete thickness.

5. Interface bonding condition was found to be a significant influencer regardless of surface layer thickness.

\section{REFERENCES}

Al-Qadi, I. L., Carpenter, S. H., Leng, Z., Ozer, H., \& Trepanier, J. (2009). Tack coat optimisation for HMA overlays: accelerated pavement test report. Illinois Center for Transportation (ICT).

Amini, F. (2005). Potential applications of paving fabrics to reduce reflective cracking (No. FHWA/MS-DOT-RD-05-174). The United States Federal Highway Administration.

Cable, J. K., Fanous, F. S., Ceylan, H., Wood, D., Frentress, D., Tabbert, T. R., ... \& Gopalakrishnan, K. (2005). Design and Construction Procedures for Concrete Overlay and Widening of Existing Pavements.

Fallah, S., \& Khodaii, A. (2015). Reinforcing overlay to reduce reflection cracking; an experimental investigation. Geotextiles \& Geomembranes, 43(3), 216-227. https://doi.org/10.1016/j.geotexmem.2015.03.002

Francois, F. B., Larson, T. D., Pennsylvania, S., Borchert, J. R., Braun, R. P., Dustin, A. G., \& Manheim, M. L. (1982). Minimising Reflection Cracking of Pavement Overlays National Cooperative Highway Research Program, National Cooperative Highway Research Program, National Research Council, Washington, DC). 
Freeman, T. E., \& Board, V. C. T. (2002). Evaluation of concrete slab fracturing techniques in mitigating reflective cracking through asphalt overlays (No. VTRC-03-R3). Virginia Transportation Research Council.

Huang, Y. H. (1993). Pavement analysis and design.

Kumara, W., Tia, M., Wu, C. L., \& Choubane, B. (2003). Evaluation of applicability of ultrathin white topping in Florida. Transportation research record, 1823(1), 39-46. https://doi.org/10.3141\%2F1823-05

Lytton, R. L. (1989). Use of geotextiles for reinforcement and strain relief in asphalt concrete. Geotextiles \& Geomembranes, 8(3), 217-237. https://doi.org/10.1016/0266-1144(89)90004-6

Lytton, R. L., Tsai, F. L., Lee, S. I., Luo, R., Hu, S., \& Zhou, F. (2010). Models for predicting reflection cracking of hot-mix asphalt overlays (No. Project 01-41). https://doi.org/10.17226/14410

Nunn, M. E. (1989). An investigation of reflection cracking in composite pavements in the United Kingdom. Proceedings of $1^{\text {st }}$ International RILEM Conference on Reflective Cracking in Pavements, Assessment \& Control, Liege University, Belgium.

Ozer, H., Al-Qadi, I. L., Wang, H., \& Leng, Z. (2012). Characterisation of interface bonding between hot-mix asphalt overlay and concrete pavements: modelling and in-situ response to accelerated loading. International Journal of Pavement Engineering, 13(2), 181-196. https://doi.org/10.1080/10298436.2011.596935

Pavement Consultancy Services (1991). Guidelines and methodologies for the rehabilitation of rigid highway pavements using asphalt concrete overlay.

Shen, S., Zhang, W., Wang, H., \& Huang, H. (2017). Numerical evaluation of surface-initiated cracking in flexible pavement overlays with field observations. Road Materials \& Pavement Design, 18(1), 221-234. https://doi.org/10.1080/14680629.2016.1138879

Sobhan, K., \& Tandon, V. (2008). Mitigating reflection cracking in asphalt overlays using geosynthetic reinforcements. Road Materials \& Pavement Design, 9(3), 367-387. https://doi.org/10.1080/14680629.2008.9690124

Thompson, M. K., \& Thompson, J. M. (2017). ANSYS mechanical APDL for finite element analysis. Butterworth-Heinemann.

Williamson, M. J. (2015). Finite element analysis of hot-mix asphalt layer interface bonding (Doctoral dissertation, Kansas State University).
Mechanistic

Responses of Asphalt Concrete Overlay Over Jointed Plain Concrete Pavement Using Finite Element Method 